\title{
Two-Sided Markets: A Tentative Survey
}

\author{
ROBERTO ROSON * \\ Department of Economics, Ca'Foscari University, Venice
}

\begin{abstract}
A recent literature, dealing with special markets characterized by bilateral network externalities, is summarized and critically assessed. Specific features of these markets, in terms of pricing principles and externalities, are discussed first. Afterwards, several issues related to competition between platforms are considered. Finally, implications for competition policy and prospects for future research are briefly discussed.
\end{abstract}

\section{Introduction}

In two-sided markets, two (or more) parties interact on a platform, and the interaction is affected by special "indirect" network externalities. Furthermore, the distribution of prices faced by the two sides influences market participation and the overall volume of demand.

The classic example is provided by credit card services. In deciding whether or not to subscribe to a specific card, consumers consider the number of merchants accepting it for payment, whereas merchants consider the number of customers wishing to use it. The value of joining a credit card "platform" depends on expectations about the opposite network size. Similar characteristics can be found in Yellow Pages directories (businesses, readers), publication software like Adobe Acrobat (authors, readers), Internet backbones and search engines (sites, surfers), shopping malls (shops, consumers), matching and employment agencies, auction houses, service vouchers networks, payment systems, some telecommunication systems, videogame consoles, scientific journals, and many others. If indirect network externalities are negative (Reisinger, 2004), the concept can be usefully applied to many media industries, in which the number of advertisers have a negative impact on readers/viewers/listeners, but of course advertisers like to get a large audience.

A market is two-sided if platforms serve two groups of agents, such that the participation of at least one group raises the value of participating for the other group. Rochet and Tirole (2004) propose a more restrictive definition, where the term "two-sided" is only applied to cases in which prices faced by agents on each side (possibly zero or negative) have a direct influence on market participation for their side, so that the volume

* Roberto Roson. Dipartimento di Scienze Economiche, Università Ca' Foscari di Venezia, Cannaregio S. Giobbe 873, 30121 Venezia. E-mail: roson@unive.it Valuable comments on an earlier version of this paper by Julian Wright and an anonymous referee are gratefully acknowledged. However, the usual disclaimer applies. 
of transactions does not merely depend on a comparison between total expected benefits and total transaction costs (a feature that has been defined as "failure of the Coase theorem").

There has been a recent surge of interest in two-sided markets, especially after the seminal papers by Armstrong (2004), Caillaud and Jullien (2003), and Rochet and Tirole (2003a). In the last couple of years, many research works have addressed diverse issues related to two-sided markets, and have considered variants of assumptions about timing, price instruments, externalities, etc. Some other papers have tried to put some order in this fast growing field, by providing general introduction, overview and discussion of "lessons" to be drawn (Evans, 2003), or general theoretical and definitional frameworks (Rochet and Tirole, 2004). However, a literature survey of the recent two-sided markets literature has not been offered to date.

This paper aims at filling this gap. This is, admittedly, a rather difficult and "dangerous" task, for two reasons. First, most of the works have not been definitively published in scientific journals, and circulate as working papers or unpublished manuscripts. Therefore, there is an unavoidable risk of forgetting some, possibly significant, contribution. Second, and more important, there is still some lack of general consensus about what constitutes key characteristics of two-sided markets, and whether or not some markets should be counted as two-sided. Therefore, I am aware that, in presenting this young literature, I shall offer my personal point of view. Despite these potential shortcomings, however, I think that a "tentative" survey could be a useful tool for those interested in this subject, and that the body of literature has grown enough to start trying to review it.

There is one puzzling aspect of the two-sided markets literature: once the concept of two-sidedness is understood, one can easily figure out how many two-sided markets there are in the real world. So, why is this literature so young? Why is it that economic theory seems to have devoted specific attention to these markets only recently? Is this literature teaching us something really new? The answer is that some two-sided markets have actually been studied for a long time, and some characteristics of two-sidedness have been noticed, but similarities between seemingly rather different businesses like, for example, consoles for videogames and matching agencies, were not highlighted previously.

For example, Baxter (1983) realized a pioneering work on credit cards. Around the year 2000 a theoretical and empirical debate developed, triggered by a series of antitrust cases against the international credit card networks (Visa, MasterCard), in the United States, Europe and Australia. Contributions come from, among others, Gans and King (2003), Katz (2001), Rochet and Tirole (2002), Schmalensee (2002), Wright (2003a; 2003b; and 2004). All these authors agree that credit card services have special characteristics, making conventional practices of antitrust policy partly not applicable to this industry. Only when these characteristics were noticed in other markets did a general theory of two-sided markets emerge. ${ }^{1}$ Since then, contributions in various fields, like competition in media industries (for example, Ferrando et al., 2004; Reisinger, 2004; and

\footnotetext{
${ }^{1}$ On the other hand, the credit card industry has also its own peculiar features. The interested reader can find a good literature survey in Chakravorti (2003).
} 
Kaiser and Wright, 2004) or electronic intermediaries (Caillaud and Jullien, 2003; and Jullien, 2004), have been formulated from a two-sided markets perspective. ${ }^{2}$

In this paper, we first discuss some peculiar features of two-sided markets, which justify a distinct theoretical treatment. We then review the basic pricing principles under a number of alternative model specifications and objective functions. In the fourth section, the issue of competition in two-sided markets is considered, with special reference to platform competition, that is, between alternative interaction networks. The difficulties associated with the application of conventional guidelines for antitrust policy is briefly considered in the fifth section, based on Evans (2003) and Wright (2003c). Finally, some concluding remarks are provided.

\section{Peculiar characteristics of two-sided markets}

Network externalities are said to exist when consumer utility in a certain market depends (usually, in a positive way) on consumption of the same good or service by other agents. ${ }^{3}$ Markets with network externalities have been widely analyzed, especially since the contributions by David (1985), Katz and Shapiro (1985), Farrell and Saloner (1985), and others.

In a sense, two-sided markets are just markets characterized by a special type of network externality. This externality does not depend on consumption of agents in the same class (for example, consumers of the same product), but on consumption of different, but "compatible", agents on an opposite market side. For example, in joining an intermediation service platform, a buyer will take into account the number of potential sellers using the same platform, in addition to the price she should pay. In other words, the opposite network size works as a sort of quality parameter in the platform adoption choice. Since the opposite network size is affected by the specific price applied to that side, the indirect utility for an agent in a two-sided market depends on both prices.

However, if agents are allowed to make side-payments, the usage fee applied to each of them would play a rather minor role in the adoption choice. For example, if a buyer and a seller would be free to negotiate a transaction price, only the total surplus, net of all transaction costs of all sides, would matter. Any cost shift, for example, from the seller to the buyer, would then be passed through, and neutralized, for example through a corresponding price reduction. ${ }^{4}$

According to the definition proposed by Rochet and Tirole (2004), such a market should not be termed "two-sided". More precisely, they define a market as two-sided if, holding constant the total of prices faced by the two parties, any change in the price structure (or distribution) would affect participation levels and the number of interactions on the platform. This would occur if costs on any side cannot be completely passed through to the other side. Thus, it would become important to consider who pays what, in order to get "both sides on board".

\footnotetext{
${ }^{2}$ Some papers cited here deal with general theories. For instance, the market for electronic intermediaries is taken as an illustrative example. On the other hand, there are other industry specific papers that could be added, like the one on journals, or other media.

${ }^{3}$ The concept can be also applied to producers, in terms of lower costs.

${ }^{4}$ In the same vein, Gans and King (2003) identify precise conditions, making the interchange fee level neutral in the credit card industry.
} 
From this point of view, the existence of indirect network externalities would not be sufficient to identify a two-sided market. On the other hand, Jullien (2004) argues that, by reducing the gains from interaction, the total price level affects participation. Increasing it would mean reducing participation of both sides of the market. In terms of externalities, it is then difficult to distinguish between one-sided or two-sided usage.

The reasons why costs may not be passed through could be both exogenous (asymmetric information, transaction costs) and endogenous. Among the latter, especially important are price structures with fixed components, independent from the number of transactions (that is, subscription fees). Another important category includes special rules, contractually defined, devoted to limiting the possibility of discrimination among agents of the opposite market side, like no-discrimination (Chakravorti and Emmons, 2001) and honor-all-cards (Rochet and Tirole, 2003b) rules in payment systems.

The nature of two-sided network externalities is determined by the characteristics of interaction processes. From the demand point of view, two main sources of externality can be singled out, depending on the interaction type:

- Single interaction externality. A single matching is realized between two entities, acting on the two market sides. Network externalities exist whenever the matching quality improves when more alternatives become available. Examples of these markets can be found in real estate, dating and employment agencies.

- $\quad$ Multiple interaction externality. Every agent gets a benefit, possibly potential, from each interaction. More interactions are possible if more partners are available. Markets of this kind can be found in telephone directories, Internet search engines and payment systems.

The two categories are not mutually exclusive. Like in any market with differentiated products, the presence of more suppliers could imply a better choice for a specific good (thereby increasing the demanded quantity), as well as the possibility of buying more goods, from different varieties.

The distinction between single and multiple interaction helps in determining the nature of the externality. In the single-interaction case, the number of agents in the opposite market side may be associated with decreasing returns on utility. In the multipleinteraction case, returns could be (almost) constant. This has implications in terms of possible emergence of corner solutions in equilibrium, with one or few platforms dominating the market. ${ }^{5}$ More generally, concave or convex relationships may emerge if elements on the opposite side are regarded as substitutes or complements.

In addition to inter-side externalities, there could be intra-side externalities, that is, among agents of the same group. An especially interesting case is the one, studied by Belleflamme and Toulemonde (2004), Anderson, Ellison and Fudenberg (2005), in which intra-side externalities are negative and inter-side externalities are positive. The obvious example is a normal market place, in which buyers like to find many potential sellers, but are also negatively affected by the presence of competitor buyers, and vice versa. ${ }^{6}$

\footnotetext{
${ }^{5}$ This case is more likely when marginal returns do not decrease too strongly, which may easily occur with multiple interactions.

${ }^{6}$ In most cases, adding intra-side externalities does not fundamentally alter the picture provided by the theory of two-sided markets. For example, having one more buyer in a market may mean that suppliers are better off (and can be charged more) and buyers are worse off (and should be charged less). In many
} 
If market equilibrium is defined as the outcome of a two stage game, where platforms set prices first, and agents on the two sides decide whether to join some platforms afterwards, there is a general problem of demand-side coordination of expectations. There could be, indeed, several equilibria for the same set of prices. For example, if negative fees are ruled out and (gross) utility on both sides is nil if no agent of the opposite side joins the platform, then a "pessimistic", zero activity equilibrium is always possible. Most of the models in the two-sided literature just assume that agents successfully coordinate on positive levels of activity. ${ }^{7}$

From the supply point of view, useful distinctions can be introduced, on the basis of the price, or non-price, instruments available for the platforms. Much of the literature has considered two classes of price instruments: membership and usage charges. Membership fees have been considered mainly in the context of market intermediation, and in all cases where transactions are not perfectly observed, or are costly to monitor. Usage fees have been considered mainly in association with credit cards and payment systems, for example in terms of merchant fees.

The use of one or the other price instrument, however, is sometimes a purely conventional choice. From the point of view of an agent on one side, who has expectations about the number of interactions carried out in equilibrium, there is always some equivalence between the two types of price (as far as price changes can be compensated, to keep expected utility constant).

The distinction between the two prices makes sense only if the choice of joining a platform is logically separated from the subsequent choice of making a certain interaction on the same platform. This is the approach taken, for example, by Caillaud and Jullien (2003), where the realization of a transaction on an intermediation platform is probabilistic. $^{8}$

Rochet and Tirole (2004) distinguish between "membership externality", occurring when additional membership on one side benefit the opposite side members, and "usage externality", occurring when an additional interaction benefits one partner agent. I think that this terminology is somehow misleading, because we are not talking about two different externalities, but actually about the same externality, assessed from two different points of view (which can be, nonetheless, usefully kept distinct). It is easier to think in terms of membership externality when membership fees are used, and in terms of usage externality when transaction fees are applied. However, the externality is only one, since it is eventually generated by the interaction of the two sides on the platform.

\section{$3 \quad$ Pricing}

The basic principles of pricing in a two-sided market can be illustrated by taking, as a reference, the case of a monopolistic, profit-maximizing platform. Suppose that this

circumstances, what really matters is the net effect on the platform profit, as well as the platform capability of internalizing network externalities (for example, when prices are set).

${ }^{7}$ Still, there can be multiple equilibria with positive activity (for example, Ambrus and Argenziano, 2004).

${ }^{8}$ In this setting, there can be side-payments between buyers and sellers, so that only the total transaction cost matter (not the price structure). Higher transaction prices reduce the probability of realization of a transaction on the platform. 
platform serves two sides ( $a$ and $b$ ), on which there are $n^{a}$ and $n^{b}$ agents, realizing a volume of interactions $I\left(n^{a}, n^{b}\right)$, which is increasing in both $n^{a}$ and $n^{b}$.

We consider the existence of membership and usage fee for each side $\left(P^{i}, p^{i}\right)$, fixed permember costs $C^{i}$, and a variable transaction cost $c$. Then, the platform profit can be expressed as:

(1) $\Pi=\left(P^{a}-C^{a}\right) n^{a}+\left(P^{b}-C^{b}\right) n^{b}+\left(p^{a}+p^{b}-c\right) I\left(n^{a}, n^{b}\right)$

Let us define the net utility obtainable by joining the platform, for agents on both sides, as:

(2) $V^{i}=U^{i}(I)-p^{i} I-P^{i}$

If baseline utility, that is, the utility obtainable by not joining the platform, is normalized to zero, all agents for which $V^{i}>0$ will join. This determines the number of interactions on the platform ${ }^{9}$, as well as the implicit demand (for membership) in terms of either $p$ or $P$.

When transaction fees are not available, some authors, (for example, Armstrong, 2004) have demonstrated that, under standard assumptions, profit maximizing membership fees should be set at:

$$
P^{i}=C^{i}+c \frac{d}{\partial n^{i}}-\frac{\partial U^{j}}{\partial I} \frac{\partial}{\partial n^{i}} n^{j}+\mu^{i}
$$

where $j$ is the opposite market side, and $\mu^{i}=-n^{i} \frac{\partial P^{i}}{\partial n^{i}}$ is the profit mark-up. ${ }^{10}$

To see how (3) can be derived, consider the number of agents $n^{i}$ as the profit maximizing "quantity" selected by the monopoly. There are two such quantities, corresponding to the two market sides. Suppose that quantity $n^{j}$ has already been optimally set. By adding an extra agent on side $i$, the utility of $j$-side agents would increase (bringing about an increase of demand beyond the optimal level). To neutralize this, membership fees on $j$ should be set higher, to keep utility constant. In turn, this implies that the actual cost of serving an extra customer on side $i$ is lower than its marginal cost.

Notice that the only difference between a standard profit-maximizing price formula and (3) is the presence of the third term on the right hand side. This has the effect of lowering the relevant marginal cost in the Lerner equation, so that the actual opportunity cost of an extra member on side $i$ is taken into account. Another equivalent interpretation is that the platform lowers the fee on one side to internalize the positive membership externality for the opposite side.

Prices set according to (3) may well turn out to be negative, if the externality effect is sufficiently strong. If negative prices cannot be applied in a market, only one side will be

\footnotetext{
${ }^{9}$ Notice that, in this setting, the number of interactions depends on the number of agents active on the two sides, not on prices (directly). This assumption is adopted in most of the papers in the two-sided markets literature, although it is not essential for the results.

${ }^{10}$ Also, the utility $U^{j}$ refers to the marginal consumer on side $j$, indifferent between joining and not joining.
} 
charged. This is an outcome often observed in many two-sided markets. As pointed out by Armstrong and Wright (2004), the impossibility of imposing negative fees on one side induces lower fees for the other side. This is an example of a general effect termed by Rochet and Tirole (2004) "topsy-turvy principle": "a factor that is conducive to a high price on one side, to the extent that it raises the platform's margin on that side, tends also to call for a low price on the other side as attracting members on that other side becomes more profitable".

Like in the case of vertical integration by firms, the act of internalizing market externalities is socially beneficial. Therefore, it is useful to keep a logical separation between the exercise of market power by the platform (socially harmful) and the objective of getting a balanced market. This second objective would be pursued even in the cases of constant profit, non-profit, or social welfare maximizing platforms. ${ }^{11}$

It has been demonstrated (Jullien, 2004; and Bolt and Tieman, 2004b) that welfare maximizing prices do not generally cover the costs. This is because positive network externalities (both one-sided and two-sided) operate like economies of scale on the demand. Like in a natural monopoly, then, welfare maximization would be associated with negative profits. On the other hand, if profits cannot be negative, a sort of Ramsey pricing emerges (Jullien, 2004).

To the extent that the platform operates like a sort of market regulator, it may try to influence the market performance with other, non-price instruments, for example by influencing the terms of trade of the two sides in the transactions (Wright, 2003a).

Rochet and Tirole (2003a) study the case in which only transaction fees, rather than membership fees, are available ${ }^{12}$, and obtain a condition similar to (3):

(4) $p^{i}=c-p^{j}+\mu^{i}$

which has a similar interpretation: every time one more interaction is carried out on the platform, this generates a marginal $\operatorname{cost} c$, but it also allows imposing an interaction price $p^{j}$ on the other side.

Combining the two conditions (4), it can be shown that the structure of prices in the two sub-markets is given by:

(5) $\frac{p^{a}}{p^{b}}=\frac{\varepsilon^{a}}{\varepsilon^{b}}$

so, interestingly, prices applied to the two market sides are both directly proportional to the price elasticity $(\varepsilon)$ of the corresponding demand. In other words, an increase in the elasticity in one sub-market increases the specific relative price.

\footnotetext{
${ }^{11}$ There can still be a conflict between market power and social welfare in the presence of some market imperfections (Rochet and Tirole, 2002). For example, it has been argued (Reserve Bank of Australia, 2002) that the willingness to accept credit cards, for a merchant, is related to the possibility of stealing customers from some competitors. As such, this willingness (to pay for credit card services) should not be fully accounted for in the aggregate social welfare, as gains for some merchants would be associated with losses for some other merchants.

${ }^{12}$ Furthermore, they assume that $I\left(n^{a}, n^{b}\right)=n^{a} n^{b}$.
} 
Bolt and Tieman (2004a) notice that this holds true only if (4) identify an interior equilibrium, which means that concavity assumptions for the profit function should be met. They show that these assumptions may actually be violated in many circumstances, where a corner solution would emerge. In this way, they offer an alternative explanation for the fact that some platforms charge only one side.

\section{$4 \quad$ Competition in two-sided markets}

Various types of competition may affect two-sided markets. Inside competition occurs between subjects within the same platform, whereas outside competition occurs between two or more platforms.

As far as inside competition is concerned, it should be noticed that belonging to a common platform does not rule out the emergence of internal competition. For example, payment card networks set compensation fees between bank members, but banks remain free to compete, having freedom in the choice of final prices for their services. A shopping mall is a two-sided market, attracting both customers and shops. Shops may still compete among themselves, though. In this case, an especially interesting question is how platform access can occur and how access prices are set (Nocke et al., 2004).

Perhaps more challenging, and complex, is the case of platform competition: for example, between alternative payment systems, newspapers and TV channels, intermediation services, shopping malls. A key characteristic of platform competition is multidimensionality. Whereas, in a conventional market, customers may be attracted through lower prices and higher utility in one market, in a two-sided context it is possible to compete in one or the other side. For example, an intermediation agency can choose between reducing the commission fees charged to the sellers, or to the buyers.

Competition may emerge "naturally", or may be the result of active behavior by one market side. In Roson (2004), I consider a competitive auction for the procurement of platform services. In this setting, the auction should be designed in such a way that the price applied to the auctioning party is not the only element considered for the selection of the winning bid, given the need to ensure sufficient participation by the other side of the market.

Schiff (2003) considers the possibility that open systems share access to one or both market sides, so that cooperation between platforms may coexist with competition. An example could be some real estate agencies, sharing directories of units for sale, or Internet backbones with peering interconnection agreements (Cremer, Rey and Tirole, 2000; Little and Wright, 2000; and Roson, 2003). Generalizing this case, one could easily conceive systems, in which access is sold to the other platforms at a price. This draws an interesting analogy between some two-sided markets and telecommunication networks, for which a wide literature on access pricing is available (for example, Laffont and Tirole, 2000).

The introduction of competition in a market, for example through the establishment of a duopoly in a formerly monopolistic market, generates two distinct effects: a reduction of market power held by the incumbent platform(s), and a change in the price structure. In the previous section, we saw that a monopolistic platform balances the two market sides through an internalization of network externalities, and that this act is, in principle, in line with social welfare maximization. When competition is introduced, the competitive pressure has effects on both the aggregate price levels and the relative prices. Relative 
prices may change because the competitive pressure may be stronger on one side. However, this translates into a "misalignment introduced by platform competition between the dominant platform's objectives and social welfare maximization" (Hagiu, 2004b).

Chakravorti and Roson (2004) compare the market equilibrium of a duopoly with the one of a cartel between differentiated platforms. They show that, when switching from the monopolistic cartel to the duopolistic competition, the effect of price reduction dominates the change on the price structure, with non-ambiguous positive effects on welfare, unless the market power of the cartel was already restricted by the nature of the platform (Rochet and Tirole, 2002), or by some other specific characteristics of the market.

This result has a simple, intuitive explanation in terms of indirect network externalities: if a buyer (seller) fee is lowered, the buyer's (seller's) welfare will increase, but also the seller's (buyer's) utility will increase, as more buyers (sellers) will be active on the market. In this way, a platform would attract more agents of both sides, taking them away from the competing platform. As a consequence, pecuniary externalities operate in the usual, "prisoner's dilemma" way, so that a competitive equilibrium will be characterized by lower prices on both sides.

To draw the conclusion that competition is socially desirable in two-sided markets, however, the potential benefits of a single-platform standardization should be taken into account. A single platform (but not a cartel between incompatible platforms) may bring about higher market prices, but would also allow for a wider customer base on both market sides, with ambiguous effects on the agents' utility (Schiff, 2003). If potentially alternative platforms provide differentiated services, a trade-off between economies of scale and differentiation emerges, as it is typical of monopolistic competition models.

Single platform standardization may be the result of market competition, in which one platform "corners" the competitor. Caillaud and Jullien (2003) discuss a model with homogeneous agents, in which only one platform is active in equilibrium, and profits are zero. Profits can become positive if heterogeneity of some kind is introduced in the model but, nonetheless, there can be asymmetric equilibria even if platforms are symmetric. For example, Ambrus and Argenziano (2004) present a model in which, in equilibrium, one platform charges more to one side and less to the other one, whereas the competitor follows a reversed price strategy.

\subsection{Platform differentiation}

Two-sided platforms may provide services, which are perceived as different by customers. Traditionally, this aspect has been neglected in the credit card literature, where it is often assumed that a consumer could select, for payment, one credit card or another, provided that they are both accepted by merchants ${ }^{13}$ (Guthrie and Wright, 2003). On the contrary, the literature on other platforms (most notably on TV channels and newspapers) has specifically addressed the issue of service differentiation, sometimes endogenously determined. ${ }^{14}$

\footnotetext{
${ }^{13}$ This is, clearly, a simplifying assumption. Credit cards do make advertisements to differentiate themselves, and their local degree of acceptance may differ. Furthermore, many credit card networks have fidelity programs. The result is that, even where consumers usually carry several cards, one card is prevalently used (Rysman, 2004).

${ }^{14}$ Think, for example, to a TV channel deciding about its type of programs: general entertainment, all sport, all news, not to mention the political orientation of its journalists.
} 
Generally speaking, differentiation in two-sided markets does not produce effects qualitatively different from those illustrated, for conventional markets, by the Hotelling duopoly model (except for the standardization effect pointed out above). Without differentiation, a special type of a Bertrand price war emerges, bringing about complete dissipation of profits for the competing platforms. One fundamental difference from the base model, however, is that equilibrium prices are not generally aligned to marginal costs. This is because the outcome of the non-cooperative game is a situation in which consumer utility is maximized, under the constraint of non-negative profits. Since utility is also a function of the market volume on the other side, the problem of price balancing emerges even when profits are zero, so that one market side typically subsidizes the other one.

\subsection{Agent differentiation}

It was previously noticed that competitive equilibrium prices depend on the intensity of competition on the two market sides. In turn, this relates to the degree of agent differentiation on the two sides. Think, for example, of the case in which sellers are indifferent between services provided by two alternative intermediaries, whereas buyers are not. Leaving aside the issue, to be considered later, of the possible adoption of both platforms, it may be easily seen that intermediaries will fight more vigorously to conquer the seller side.

This holds in general. Still, there are two ways to convince a seller: a low commission fee (even nil or negative), or a larger base of potential buyers. Introducing competition will bring about reductions in prices, but which market side will gain more? The side that will gain more is determined by two factors: (a) the relative degree of agent differentiation, and (b) the relative importance of network externalities (Chakravorti and Roson, 2004).

When agents regard the competing platforms as offering different services, we may speak of horizontal differentiation. Gabszewicz and Wauthy (2004) consider instead a case of vertical differentiation, in which agent utility, for example for the side $a$, is defined as:

$$
V^{a}=\theta n^{b}\left(P^{b}, P^{a}\right)-P^{a}
$$

and the parameter $\theta$ takes different values among the agents, according to some distribution function.

When agents on a two-sided platform are differentiated, the pricing policy can have an impact on utility through some selection mechanisms. Damiano and Li (2003) discuss a model in which the average quality of matches on the other side depends on platform pricing, like in the case of clubs, whose members are snobs, or dating agencies, whose clientele prefers to meet wealthy people.

\subsection{Multihoming}

The term multihoming, which originated in the technical jargon of Internet, is now universally used to define those situations in which some agents, in one or both sides of a two-sided market, adopt more than one platform, so that interactions may occur through a series of alternative channels. A shop manager multihomes when several credit cards are accepted for payment. A consumer multihomes when she owns several credit cards, among which to choose. Other multihoming examples are: advertisers using multiple media, 
computers having installed more than one operating system, house sellers dealing with multiple real estate agents.

Multihoming can be more easily observed when fixed costs of joining a platform are low or absent. For example, if per-transaction fee is the more significant cost element for merchants, more than one credit card will likely to be accepted for payment by the same business. On the contrary, if consumers pay only a fixed subscription fee, they will tend to use a single credit card, especially if credit cards offer comparable services and have similar degrees of acceptance among merchants.

Adding multihoming makes the formulation and analysis of two-sided markets considerably more complex. To keep the analysis tractable, many authors just assume, on the basis of the specific characteristics of the markets at hand, which market side multihomes. Other authors adopt special assumptions ${ }^{15}$, which allow them to know in advance which side will eventually multihome in equilibrium. ${ }^{16}$

A major difficulty in dealing with multihoming is given by the possibility of steering adoption choices by agents on the opposite side. As an example, consider the case of a merchant, who could accept for payment both a credit card and a debit card. It will not suffice to verify that there exist positive transaction benefits in both cases, to conclude that both cards will be accepted. If, say, transaction fees are significantly higher for the credit card, the merchant could just refuse to accept the credit card, in order to force the consumers to use her most preferred payment instrument.

Clearly, the presence of multihoming on one market side influences the degree of competition. The competitive pressure will be stronger wherever a platform can get rid of its competitors, which occurs more easily where singlehoming prevails. ${ }^{17}$ As it has already been noticed, the instruments for the competitive fight are lower prices, or larger network volumes on the opposite market side.

\subsection{Endogenous adoption}

The choice of joining one or more platforms should be, in principle, endogenously determined within a model of platform competition. Unfortunately, introducing endogenous platform adoption can easily make the models overwhelmingly complex, and this explains why, as noted above, most authors prefer to take shortcuts, allowing to specify ex-ante the single/multihoming structure of the markets at hand. There are, however, a few papers which have recently addressed special cases of endogenous joining.

Hermalin and Katz (2004) present a model in which there are no network externalities, platform services are horizontally differentiated for heterogeneous agents, and there are variable usage fees, but no membership fees. Reciprocal (both sides) multihoming is a possible equilibrium outcome, because agents are heterogeneous in terms of transaction benefits, which are platform-specific. Results critically depend on which side has the power of selecting the network under multihoming, that is, when alternative platforms are available. Agents on the selecting side will opt - whenever possible - for the platform providing highest net transaction benefits, but will join both networks (if net benefits are

\footnotetext{
${ }^{15}$ For example, parameter homogeneity for one market side.

${ }^{16}$ This may not be an analytical "trick". For example, in many settings it is quite natural that sellers view the platforms as homogenous, while buyers do not (view platforms as heterogeneous). See Armstrong and Wright (2004) for a discussion.

${ }^{17}$ Rochet and Tirole (2003b) notice that, when merchants can steer consumers, this "veto" right makes the competition more intense on their side.
} 
non-negative) to prevent the case of facing a partner operating only on the other platform. Agents on the non-selecting side face a trade-off: by singlehoming, they could steer potential partners on their preferred network, but they could also lose some partners, who singlehome on their less preferred network. The amount of singlehoming partners, however, depends on market prices. If platforms apply zero transaction fees, all agents on the selecting side will join both platforms. But then, non-selecting agents will all singlehome on their preferred network, thereby determining which platform will be ultimately used!

Gabszewicz and Wauthy (2004) assume, on the contrary: network externalities (network volume is similar to quality in models with vertical differentiation), membership fees (no variable usage fees), heterogeneous agents in terms of sensitivity to network externalities. In their framework, there can be multiple equilibria in the platform competition game, but in only one equilibrium there are positive profits for all platforms. In this case, one side multihomes, whereas the other one singlehomes: there cannot be reciprocal multihoming in equilibrium. The intuition is simple: there is no scope to multihome when agents of the other side are already present in all platforms. To get reciprocal multihoming, it is essential that not all agents in the other side multihome, which may occur only when platforms are horizontally differentiated on both sides of the market.

More generally, the possibility of choosing between single and multihoming exacerbates the coordination problems faced by agents on both sides, thereby making the existence of multiple equilibria more likely (see, for example, Armstrong and Wright, 2004). In addition to a coordination problem in terms of network size expectations, agents should coordinate in terms of adoption choices (they should successfully anticipate which sides will multihome, for example).

In a recent work (Roson, 2005), I discuss a model of payment card competition with endogenous single/multihoming. The structure of the model is similar to that of Hermalin and Katz (2004), except for the presence of two-sided externalities, and the pre-assigned right of the consumers to choose the preferred card in the transactions (when possible). On the basis of prices selected by the competing platforms (membership and variable usage fees) consumers and merchants play a coordination game, as adoption choices on the two sides are interdependent. Not surprisingly, there can be multiple equilibria.

In a specific market equilibrium with two competing platforms, the set of merchants is partitioned in four sub-sets: non-joiners, singlehomers on platform 1, singlehomers on platform 2, multihomers. Consumers are partitioned in a similar way, but multihomers are further distinguished between those who would select one network whenever possible, or the other one. If all subsets are not empty in equilibrium ${ }^{18}$, the competitor networks can use the four price instruments at hand (membership and usage fees for the two sides) to address four categories of customers: singlehoming consumers, multihoming consumers, singlehoming merchants, multihoming merchants. If one or more subsets are empty, some price instruments are redundant (under perfect foresight about the number of transactions in equilibrium), as it was pointed out in the previous section.

Armstrong and Wright (2004) consider the possible existence of strategies specifically designed to infuence adoption choices: exclusive deals. They first derive conditions under which, in a certain two-sided market, one side multihomes and the other one singlehomes. They then consider the possibility that a platform proposes to the agents of the

\footnotetext{
${ }^{18}$ This requires a sufficient degree of heterogeneity among agents and platforms.
} 
multihoming side a "disounted" price, contingent on exclusivity (singlehoming on that platform). They demostrate that this would undermine the competitive equilibrium obtained in the base case, as exclusive contracts allow a special type of undercutting. A complete characterization of equilibria with exclusive deals, however, proves to be difficult: depending on model parameters and selection criteria, there can equilibria with both platforms active, or only one, and with or without exclusive contracts.

\subsection{Dynamics}

To create a two-sided market, a "chicken or egg" problem has to be solved (Caillaud and Jullien, 2003): to convince some buyers to adopt a certain intermediation platform, it is necessary to convince first some sellers, but to convince the sellers, there must be some buyers on the market.

In most models, this problem is avoided by assuming the simultaneous arrival of agents on the two market sides, in a rational expectations equilibrium. However, there are circumstances in which one market side has to intervene before the other one. The most cited case is the one of videogame consoles which, to get customers, must appear on the market already equipped with a complete range of games and complementary applications.

To get the complementary software developed, some strategies are typically followed, like the under-cost provision of development kits, and of other support material. A fundamental issue is the capability of credibly influencing the agents' expectations about future network volumes. Especially important, in his context, is the possibility of selfcommitment towards future price strategies. The existence of credible commitment changes in a substantial way the dynamic game, increasing the number of available price strategies (Hagiu, 2004b).

An interesting solution is also the integration, temporary or permanent, devoted to directly produce the complementary goods and services. For example, the handheld computers producer Palm has, at first, directly supplied most of the complementary software needed to get its hardware fully functional. When the product got a good market penetration, Palm has withdrawn from the software market, leaving the field to independent developers (Evans, 2003).

In other contexts, market entry is sometimes obtained from contiguous segments. For example, debit cards were initially introduced for cash withdrawal. Only later, these cards started to be used as a payment instrument but, at that time, they were already sufficiently diffused among consumers, so that only one market side (the merchants) had to get on board.

\subsection{Asymmetric platform competition}

To retain analytical tractability, most models assume symmetry among competing platforms. Yet, departing from these assumptions can often shed light on some interesting issues.

Chakravorti and Roson (2004) consider a "perturbation" of a symmetric equilibrium of platform competition. In line with the "topsy-turvy principle", mentioned earlier, a factor conducive - say - to a price reduction on the side $a$ for one platform will induce a price increase on the opposite side $b$. However, the competing platform will react to these price changes by increasing the price for side $a$, and decreasing it for side $b$ : in terms of price structure, the two platforms move to opposite directions. 
This is similar to what happens in an asymmetric Hotelling duopoly, where a cost disadvantage for one firm translates into a lower market price for that firm and a higher price for the competitor. Here, in addition, any price change on one side brings an opposite variation for the other side, by all platforms in the market (see equation 4).

Fahri and Hagiu (2004) add that a cost reduction for one platform on one side may raise profits for the competing platform, even if platform services are substitutes on all sides. This is because a duopolistic equilibrium may entail cross-subsidization between the two market sides (price may be below cost on one side). Furthermore, the price structure reflects both the need to get all sides on board, and the relative intensity of competition. As mentioned above, if one platform lowers the price on one side, the competitor will also change its price structure, for example by lowering the price on one side and increasing it on the other side. The competitor's profit may turn out to be higher, if the price rise takes place on the subsidized side.

Hagiu (2004a), Economides and Katsamakas (2004), Katsamakas and Bakos (2003), analyze competition between platforms with different ownership. More precisely, they study the case of competition between a proprietary platform and a non-proprietary, open access platform. The typical example considers a proprietary operating system (Windows) and an open-source one (Linux). In so doing, these authors establish a link with another nascent literature: that on open-source software (Lerner and Tirole, 2001, 2002; and Mustonen, 2003).

This case is especially interesting because, on one hand, a non-proprietary, non-profit platform by definition does not have market power, so it can only "charge" direct marginal costs but, on the other hand, it fails to internalize the two-sided externalities, since it cannot cross-subsidize one market side with the other one (as a proprietary platform can do).

Hagiu (2004a) sets up a model in which there is free entry in the market for complementary software, within a monopolistic competition setting. He shows that "if applications are differentiated and consumers are interested in one application (the Salop framework), then a two-sided sponsored platform will choose a number of applications lower than that generated by a non-sponsored platform but higher than that chosen by a welfare maximizing social planner, so that a two-sided proprietary platform is preferable to a non-sponsored platform, as it reduces the inefficiency of excessive entry. However, the opposite result holds when applications are homogeneous and users have a taste for variety: the two-sided sponsored platform exacerbates the problem of insufficient entry, since it chooses a number of applications inferior to that generated by a non-sponsored platform, which is itself less than the socially optimal number."

\section{$5 \quad$ Implications for competition policy}

In two-sided markets, the application of antitrust procedures must face special difficulties which, in some cases, may bring about erroneous conclusions. The common denominator of most erroneous applications of the antitrust methodology is the lack of understanding of the typical nature of two-sided markets, especially about the interdependence of agents' decisions in the sub-markets.

The most trivial error is considering a single sub-market in isolation. Given the need to have both parties involved (getting both sides on board), a price set above marginal or 
average costs is not a symptom of market power, as well as a price below cost is not a symptom of predatory behavior, and the combination of the two above cannot be interpreted as a presence of cross subsidies (Wright, 2003c). Even under pure Bertrand competition prices are not, in general, aligned to costs, despite the fact that profits are completely dissipated.

Another typical mistake is the erroneous interpretation of the nature of some instruments, like the interchange fee in credit card networks. Contrary to what was stated in some recent antitrust cases, the interchange fee is not a price that covers transaction costs, but it is rather an instrument used by payment networks to get the right balance of prices in the sub-markets. Any intervention devoted to bring this fee in line with need not increase welfare, and will not necessarily induce competing networks to change their price structure in a similar way. Finally, fostering network competition does not necessarily bring about a more efficient interchange fee.

Because of this, tying practices (usually forbidden by antitrust legislation) may have a rather special interpretation in a two-sided setting. Rochet and Tirole (2003b) present a model in which competition takes place between two competitor platforms, offering identical services. However, one of the platforms also acts as a monopolist in a second two-sided market. By tying the products sold in the two markets, the multi-market platform can achieve a better price balance (from the platform, as well as from the social welfare point of view), since it becomes less vulnerable to competitive pressure. In addition, Jullien (2004) notices that tying can be a device to credibly commit about network size in a two-sided market equilibrium, which is based on agents' expectations.

Finally, the existence of a significant installed base on one side should not be interpreted as a barrier to entry in the opposite sub-market. For example, in the famous Microsoft antitrust case, it has been argued that the existence of a wide range of application programs available for Windows is an obstacle to entry of competitors in the market for operating systems. Still, the mere existence of network externalities is a natural, not pathological, condition in two-sided markets (Evans, 2003).

\section{$6 \quad$ Concluding remarks}

Two-sided externalities are pervasive and important phenomena in modern economies. Yet, a specific literature on two-sided markets has emerged only recently, largely as a spinoff of the literature on credit cards and, to a lesser extent, of the literature on media industries and intermediation platforms. Not surprisingly, the two-sided markets literature appears well developed in those areas in which the analogy with the markets mentioned above fits well, whereas research is lagging behind in other areas, in which a more original approach may be necessary.

Nash equilibrium in simultaneous games of fulfilled expectations is the dominant theoretical paradigm. On the other hand, dynamics is a much less studied subject, with a good growth potential. Cases in which expectations can be revised over time appear to be especially worth to explore, as well as dynamic platform competition.

Another uncovered area is empirical research. The very few available studies address specific issues of specific two-sided markets. More general empirical research, complementing the fast-growing body of theoretical literature, is still missing. 


\section{$7 \quad$ References}

Ambrus, A. and Rossella A. (2004) "Network Markets and Consumers Coordination," CESifo Working Paper 1317.

Anderson, R.M., Ellison, G., and D. Fudenberg (2005) "Location Choice in Two-Sided Markets with Indivisible Agents," mimeo, University of California at Berkeley.

Armstrong, M. (2004) "Competition in Two-Sided Markets," mimeo, University College, London.

Armstrong, M. and J. Wright (2004) "Two-Sided Markets, Competitive Bottlenecks and Exclusive Contracts," mimeo, University College, London, and National University of Singapore.

Baxter, W. F. (1983) "Bank Interchange of Transactional Paper: Legal and Economic Perspectives," Journal of Law \& Economics, 26: 541-588.

Belleflamme, P. and E. Toulemonde (2004) "Competing B2B Marketplaces," mimeo, CORE Louvain and Lausanne University.

Bolt, W: and A. F. Tieman (2004a) "Skewed Pricing in Two-Sided Markets: An IO Approach," DNB Working Paper 13, October.

Bolt, W. and A. F. Tieman (2004b) "A Note on Social Welfare and Cost Recovery in TwoSided Markets,” DNB Working Paper 24, December.

Caillaud, B. and B. Jullien (2003) "Chicken \& Egg: Competition among Intermediation Service Providers," RAND Journal of Economics, 24: 309-328.

Chakravorti, S. (2003) "Theory of Credit Card Networks: A Survey of the Literature," Review of Network Economics, 2: 50-68.

Chakravorti, S. and W.R. Emmons (2001) "Who Pays for Credit Cards?" mimeo, Federal Reserve Bank of Chicago.

Chakravorti, S. and R. Roson (2004) "Platform Competition in Two-Sided Markets: The Case of Payment Networks," Federal Reserve Bank of Chicago Emerging Payments Occasional Paper Series, 2004-09.

Cremer, J., Rey, P. and Tirole J. (2000) "Connectivity in the Commercial Internet," Journal of Industrial Economics, 48: 433-472.

Damiano E. and H. Li (2003) "Price Discrimination in Matching Markets," Working Paper, University of Toronto.

David, P. (1985) "Clio and the Economics of QWERTY," American Economic Review, 75: 332-336. 
Economides, N. and E. Katsamakas (2004) "Two-Sided Competition of Proprietary vs. Open Source Technology Platforms and the Implications for the Software Industry," mimeo, Stern School of Business, New York University.

Evans, D. (2003) "The Antitrust Economics of Multi-Sided Platform Markets," Yale Journal on Regulation, 20: 325-82.

Fahri, E. and A. Hagiu (2004) "Tying in Two-Sided Markets: Fat Cat, Top Dog, Lean and Hungry Look or Puppy Dog?” mimeo, MIT and Princeton University.

Farrell, J. and G. Saloner (1985) "Standardization, Compatibility and Innovation", Rand Journal of Economics, 16: 70-83.

Ferrando, J., Gabszewicz, J. J., Laussel, D. and N. Sonnac (2004) "Two-Sided Network Effects and Competition: An Application to Media Industries," mimeo, CREST-LEI and EUREQUA CORE, Université Catholique de Louvain GREQAM, Université de la Méditerranée CREST-LEI and Université de Paris II.

Gabszewicz, J. J. and X. Y. Wauthy (2004) "Two-Sided Markets and Price Competition with Multi-homing," mimeo, CORE, Louvain-la-Neuve University.

Gans, J. S. and S. P. King (2003) "The Neutrality of the Interchange Fees in the Payment System," Topics in Economic Analysis \& Politics, 3, article 1.

Guthrie, G. and J. Wright (2003) "Competing Payment Schemes," Working Paper No. 0311, Department of Economics, National University of Singapore.

Hagiu, A. (2004a) "Two-Sided Proprietary vs. Non-Proprietary Platforms," in: Platforms, Pricing, Commitment and Variety in Two-Sided Markets, Ph.D. Dissertation, Princeton University.

Hagiu, A. (2004b) "Optimal Pricing and Commitment in Two-Sided Markets," in: Platforms, Pricing, Commitment and Variety in Two-Sided Markets, Ph.D. Dissertation, Princeton University.

Hermalin, B. E. and M. L. Katz (2004) "Your Network or Mine? The Economics of Routing Rules," mimeo, UC Berkeley.

Jullien, B. (2004) "Two-Sided Markets and Electronic Intermediaries," CESifo Working Paper 1345.

Kaiser U. and J.Wright (2004) "Price Structure in Two-Sided Markets: Evidence from the Magazine Industry," mimeo, University of Southern Denmark at Odense.

Katsamakas, E. and Y. Bakos (2003) "Design and Ownership of Two-sided Networks," Working Paper, Stern School of Business, New York University.

Katz, M. L. and C. Shapiro (1985) "Network Externalities, Competition, and Compatibility," American Economic Review, 75: 424-440. 
Katz, M. L. (2001) Reform of Credit Card Schemes in Australia II. Sydney: Reserve Bank of Australia.

Lerner, J. and J. Tirole (2001) "The Open Source Movement: Key Research Questions," European Economic Review, 45: 819-826.

Lerner, J. and J. Tirole (2002) "Some Simple Economics of Open Source," Journal of Industrial Economics, 50: 197-234.

Laffont, J. and J. Tirole (2000) Competition in Telecommunications. Cambridge: MIT Press.

Little, I., and J. Wright, (2000) "Peering and Settlement in the Internet: An Economic Analysis," Journal of Regulatory Economics, 18: 151-173.

Mustonen, M. (2003) "Copyleft - The Economics of Linux and Other Open Source Software," Information Economics and Policy, 15: 99-121.

Nocke, V., Peitz, M. and C. Stahl (2004) "Platform Ownership in Two-Sided Markets," mimeo, University of Pennsylvania and University of Mannheim.

Reisinger, M. (2004) “Two-Sided Markets with Negative Externalities,” Discussion Paper 2004-27, University of Munich.

Reserve Bank of Australia (2002) Reform of Credit Card Schemes in Australia IV. Final Reforms and Regulation Impact Statement. Public Document.

Rochet, J., and J. Tirole (2002) "Cooperation among Competitors: The Economics of Payment Card Associations," RAND Journal of Economics, 33: 549-570.

Rochet, J., and J. Tirole (2003a) "Platform Competition in Two-Sided Markets," Journal of European Economic Association, 1: 990-1029.

Rochet, J., and J. Tirole (2003b) "Tying in Two-Sided Markets and The Impact of the Honor All Cards Rule," mimeo, IDEI University of Toulouse.

Rochet, J., and J. Tirole (2004) "Two-Sided Markets: An Overview," mimeo, IDEI University of Toulouse.

Roson, R. (2003) "Incentives for the Expansion of Network Capacity in a Peering Free Access Settlement," Netnomics, 5: 149-159.

Roson, R. (2004) "Auctions in a Two-Sided Network: the Case of Meal Vouchers," mimeo, Ca'Foscari University of Venice.

Roson, R. (2005) "Platform Competition with Endogenous Multihoming," in Dewenter, R., Haucap, J. (eds.), Access Pricing: Theory, Practice, Empirical Evidence. Amsterdam: Elsevier Science, forthcoming. 
Rysman, M. (2004) "An Empirical Analysis of Payment Card Usage," mimeo, Boston University.

Schmalensee, R. (2002) "Payment Systems and Interchange Fees," Journal of Industrial Economics, 50: 103-122.

Schiff, A. (2003) "Open and Closed systems of Two-sided Networks," Information Economics and Policy, 15: 425-442.

Wright, J. (2003a) “Optimal Card Payment Systems," European Economic Review, 47: $587-612$

Wright, J. (2003b) "Pricing in Debit and Credit Card Schemes", Economics Letters, 80: 305-309.

Wright, J. (2003c) "One-sided Logic in Two-sided Markets," mimeo, National University of Singapore.

Wright, J. (2004) "The Determinants of Optimal Interchange Fees in Payment Systems," Journal of Industrial Economics, 52: 1-26. 